\title{
Article \\ The Impact of China Carbon Emission Trading System on Land Use Transition: A Macroscopic Economic Perspective
}

\author{
Yingkai Tang ${ }^{1}$, Yunfan Yang $^{1}$ and $\mathrm{He} \mathrm{Xu}^{2, *}$ (I) \\ 1 Department of Accounting and Corporate Finance, Business School, Sichuan University, \\ Chengdu 610064, China; tang@scu.edu.cn (Y.T.); 2018325020045@stu.scu.edu.cn (Y.Y.) \\ 2 Department of Investment, Management Science and Engineering School, \\ Central University of Finance and Economics, Beijing 102206, China \\ * Correspondence: hexu@email.cufe.edu.cn
}

Citation: Tang, Y.; Yang, Y.; Xu, H. The Impact of China Carbon Emission Trading System on Land Use Transition: A Macroscopic

Economic Perspective. Land 2022, 11, 41. https://doi.org/10.3390/ land 11010041

Academic Editors: John Tomaney and Tamara Antonia Krawchenko

Received: 8 November 2021

Accepted: 27 December 2021

Published: 28 December 2021

Publisher's Note: MDPI stays neutral with regard to jurisdictional claims in published maps and institutional affiliations.

Copyright: (C) 2021 by the authors. Licensee MDPI, Basel, Switzerland. This article is an open access article distributed under the terms and conditions of the Creative Commons Attribution (CC BY) license (https:// creativecommons.org/licenses/by/ $4.0 /)$.

\begin{abstract}
The carbon emission trading system (CETS) is a milestone policy in the history of China's emission trading system, which is of great significance to China's realization of "carbon peak and carbon neutralization". As an important component of sustainable development, LUT should be related to the CETS. However, in the literature on the CETS, little material deals with its impact on land use transition (LUT). This paper will enrich this literature. Based on 30 provincial regions in China from 2011 to 2017, using the DID and entropy methods, this study investigated the impact of CETS on the trend of LUT from three perspectives: economic effects, environmental effects and Porter effects. The conclusions are that (1) the implementation of the CETS hindered economic development, but optimized energy-use efficiency; (2) the implementation of the CETS reduced the emissions of $\mathrm{CO}_{2}$ and $\mathrm{SO}_{2}$; (3) the implementation of the CETS did not produce a Porter effect; and (4) the influence of the CETS had the characteristics of a spatial cluster. These findings offer some guidance for improving CETS policies and formulating similar environmental regulation policies.
\end{abstract}

Keywords: carbon emission trading system; land use transition; sustainable development; difference-in-difference

\section{Introduction}

A "regulation" is a general rule or a special act that is developed and implemented by an administrative body with the purpose of directly intervening in the market allocation mechanism, or indirectly changing the supply and demand decisions between enterprises and consumers [1]. The actor of regulation is usually a state administrative agency with administrative power and its behavior towards the regulated object is generally forced. Environmental regulation is one of the regulatory instruments that aims to harmonize the relationship between the economy and the environment. The emission trading system (ETS) is one of the most promising and effective environmental regulation tools [2] and one of the hot spots of research in China. Scholars have focused their research into ETS on corporate decision-making under the system, spillover effects between the system and other markets, and governmental allocations of emission rights [3]. The carbon emission trading system (CETS) is one of the ETSs and its implementation is a general trend. In 2010, China's per capita carbon emissions rose to the G20 countries' average (Source: https: //www.climate-transparency.org/wp-content/uploads/2016/02/CP_CHINA_2015, accessed on 25 October 2021) and by 2016, China's per capita greenhouse gas emissions were 8.8 tons of carbon dioxide equivalent, 17\% higher than the G20 average (Source: https: / /www.climate-transparency.org/wp-content/uploads/2019/11/B2G_2019_China, accessed on 25 October 2021). Although China's per capita carbon emissions are far lower than those of developed countries, such as the United States, they still need to be taken seriously. The CETS policy is undoubtedly a milestone in China's emission reduction history [4] and it is strategically important for China to successfully achieve the goal of 
"peak carbon by 2030 and carbon neutral by 2060". The CETS began with the Twelfth Five-Year Plan (State Council of the People's Republic of China, 2011), which promotes market mechanisms to achieve greenhouse gas emission reductions at a lower cost as an action objective. The CETS policy mainly covers eight industries, including petrochemical, chemical engineering, building, iron and steel, nonferrous metal, paper making, electric power, and air transportation. During the pilot period, the carbon emissions of more than 2000 entities were limited [5].

As an important research component of the Global Land Project (GLP), the study of land use transition (LUT) is of great significance for optimizing land use, improving resource efficiency, adjusting industrial structure, and promoting sustainable development; it has therefore received widespread attention from scholars [6,7]. The concept of LUT was initially proposed by Grainger in his studies on forested countries $[8,9]$ and later extended by scholars to other research objects, such as industrial land [10,11]. Meanwhile, LUT has been studied at a variety of object levels, including the national level [12,13], the urban cluster level [14,15], the city level $[16,17]$, and the county level [18]. LUT initially primarily referred to the long-term and trend changes in regional land use patterns $[9,19,20]$. Land use patterns record the characteristics of socioeconomic development and also, in turn, influence socioeconomic development. This bilateral interaction contributes to LUT [21,22]. Therefore, in research into LUT, it is also important to explore ways to manage land resources and promote sustainable regional socio-economic development. $\mathrm{Xu}$ et al. pointed out that LUT is related to the historical characteristics of subjects, social attributes, economic conditions, and the ecological environment [23]. Van et al. found that important policies are likely to change land use substantially [24]. Additionally, LUT is closely related to the global carbon cycle [25] and to greenhouse gases [26].

From the above analysis, it is clear that there must be a close connection between CETS and LUT. However, after reviewing the relevant literature, we found that, on one hand, studies on LUT have mainly focused on the transition process, model, and driving mechanism of LUT [27-30]. In recent years, the related literature on LUT has gradually shifted to the socio-economic effects [31,32], environmental-ecological effects [33-35], and the mechanisms of interaction with land resources management, rural transition and cities [36-39]. On the other hand, studies on the CETS have focused on its environmental, economic, and Porter effects. In terms of environmental effects, the main focus has been on its emission reduction [40] and energy saving effects [41].

In terms of economic effects, the main focus has been on the mechanism of its impact on economic growth [42]; such as promoting industrial transformation [43], expanding employment [44], and so on. The Porter effect refers to the ability of environmental regulation to promote innovation in enterprises [45], which is a current research hotspot in the field of CETS. Jiang et al. have demonstrated the existence of the Porter effect in some environmental regulation policies in China [46]. Zhou and Tan and Hu et al. have demonstrated the Porter effect of the CETS at the provincial and firm levels, respectively [47,48]. $\mathrm{Lv}$ and Bai found that high carbon trading prices and high price volatility promote firm innovation [49], while Lyu et al. found that low carbon technology innovation is increasing year by year under the CETS [50]. However, Chen et al. found that the CETS reduced the proportion of green patents due to firms choosing to reduce their output rather than increase their green innovation in order to achieve their emission reduction targets [51]. Dong et al. made the judgment that the CETS achieved emission reductions in the short term, but could not increase GDP. However, in the long term, the CETS-generated Porter effect coexisted with emissions reductions and economic development [52]. In general, the literature can be summarized into two aspects: first, that which is exploring whether the CETS can produce the Porter effect and, second, that which is exploring the impact scope of the CETS in producing the Porter effect; e.g., Shen et al. found that emission charges are effective in green process innovation [53], while Zhu et al. found that the innovation incentive effect of the CETS does not exclude other technological innovations [54], Du et al. found that there is a negative spatial spillover effect of the CETS [55], and so on. Few papers 
have explored the effect of CETS on LUTs. Our study aims to fill this gap (see Figure 1 for the technical path).

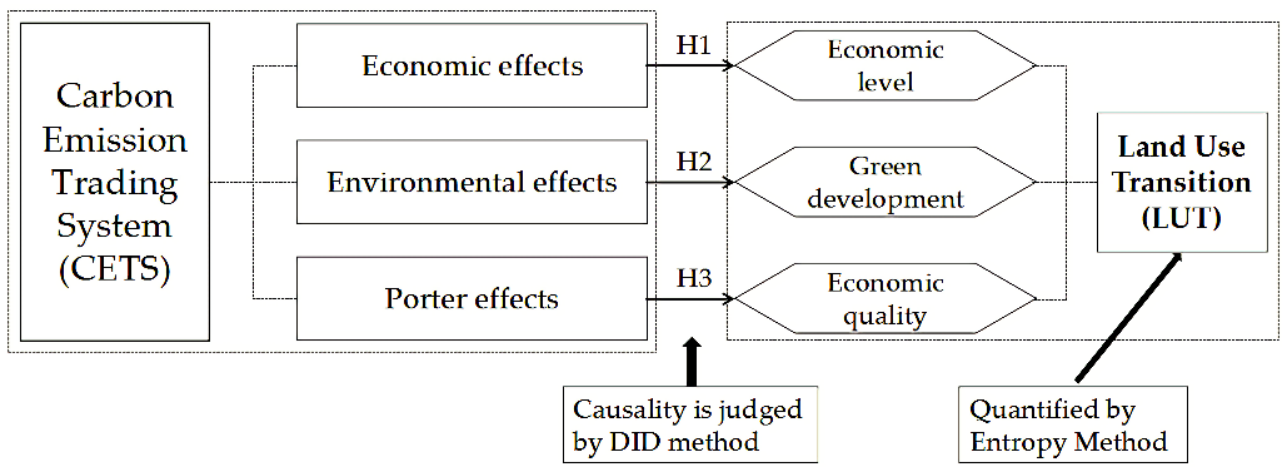

Figure 1. Technical path.

The CETS has economic effects. It not only forms a green economy, but also accompanies industrial structural upgrading and social welfare improvement. As the CETS will lead to an increase in production costs, enterprises will reduce the cost of environmental management per unit of product by increasing their production. Alternatively, enterprises will try to improve product quality, increase profit per unit of product, and even enter new industries with low energy consumption and low pollution in order to develop. In addition, the compensation strategy of the CETS will also benefit some enterprises [56]. However, as Dong et al. argued (as noted above), the short-term impact of the CETS on the economy is likely to be negative [52], even if the policy compensates for some of the losses of the firms [56], since a shift in production strategies and business policies, etc., cannot be accomplished in the short run. Considering the limitation in the scope of the data, the sample interval of this paper is short. Therefore, this paper proposes:

Hypothesis $\mathbf{1}$ (H1). the implementation of the CETS promotes land use transition in the pilot areas toward economic development, but will have a negative impact on the economy in the short term.

The CETS has an environmental effect in that its required emission restrictions force firms to improve their resource use efficiency and reduce consumption, it expels from the market those firms that are pollution-intensive but cannot reasonably manage their pollution [57], and it stimulates firms to invest more in pollutant reduction and treatment [58]. Therefore, this paper proposes:

Hypothesis $\mathbf{2}$ (H2). the implementation of CETS promotes land use transition in pilot areas toward green development.

The CETS also has a Porter effect. China's factor-driven, crude growth approach leads to low resource utilization and low economic efficiency of resources [59], meaning it is not a high-quality economic development model. In contrast, the innovation-driven model is key to improving productivity and driving economic transition $[60,61]$, which is important to achieving high-quality economic development in China [62]. Therefore, this paper proposes:

Hypothesis $3 \mathbf{~ ( H 3 ) . ~ t h e ~ i m p l e m e n t a t i o n ~ o f ~ t h e ~ C E T S ~ p r o m o t e s ~ l a n d ~ u s e ~ t r a n s i t i o n ~ i n ~ t h e ~ p i l o t ~}$ areas toward high-quality economic development.

The marginal contributions of this paper relate to the driving mechanisms of LUT. We found that there is a lack of research on the CETS policies and LUT within the same research framework and few studies have been conducted from an economic perspective. 
Second, the causal relationship between the CETS and LUT is more convincingly identified through the DID estimation method.

The rest of this article is structured as follows. Section 2 focuses on the study methods, variable design, and data sources. Section 3 describes the findings of this study and the corresponding testing procedures. Section 4 discusses the findings of the previous sections and draws out the conclusions that were obtained from this study.

\section{Methods and Data}

\subsection{Difference-in-Difference Model}

To assess the treatment effect of a policy or event, economists often use a counterfactual framework, referring to the difference between data that are treated (the treatment group) and data that are not treated (the control group) as the "treatment effect." Differencein-difference (DID) is the measure that is most widely used to estimate the treatment effect. The original logic of the method was proposed by Snow in his study on the cholera epidemic in London [63] and it was introduced into economics by Obenauer in his study on the treatment effect of the minimum wage method [64]. To estimate the treatment effect and compare the difference before and after a policy or event, the method assesses the before-and-after change in the treatment group minus the before-and-after change in the control group, hence the name "difference-in-difference". Therefore, DID is often used to identify causal relationships between explained and explanatory variables. If the model satisfies the parallel trend assumption, then the difference-in-difference method can be used directly. Stata 15 software was used to execute the model.

When DID uses panel data, a two-way fixed effects model is usually applied. Based on this, the DID model incorporates the interaction term of the treatment group dummy variable $\left(\right.$ Treat $\left._{i}\right)$ and the treatment period dummy variable $\left(\right.$ Post $\left._{t}\right)$. The basic form of the model is as follows:

$$
Y_{i, t}=\alpha+\text { Breat }_{i} \times \text { Post }_{t}+\mu_{i}+\gamma_{t}+\varepsilon_{i, t},
$$

where $i$ denotes the individual and $t$ denotes time. $Y_{i, t}$ is the explained variable. The variable $\mu_{i}$ is the province fixed effect; $\gamma_{t}$ is the year fixed effect; and $\varepsilon_{i, t}$ is the random error term.

Treat $_{i}$ is the treatment group dummy variable, which takes the value of 1 if individual i belongs to the "treatment group" that was subject to the policy shock; otherwise, it takes the value of 0 . Post $t_{t}$ is the treatment period dummy variable, whereby individuals in the treatment group were subject to the policy shock only during the treatment period. Therefore, if time $t$ belongs to the "treatment period", it takes the value of 1 ; otherwise, it takes the value of 0 .

Finally, the implications of this study are given in Equation (1) and some of the labels were adjusted in order to obtain the model that was used in this paper.

$$
\operatorname{LUT}_{i, t}=\alpha+\beta \text { Treat }_{i} \times \text { Post }_{t}+\mu_{i}+\gamma_{t}+\varepsilon_{i, t}
$$

where $\operatorname{LUT}_{i, t}$ is the land use transition variable and Treat ${ }_{i} \times$ Post $_{t}$ is the treatment variable of the CETS. Figure 2 shows the distribution of the pilot areas of the CETS policy at the provincial level in China. 


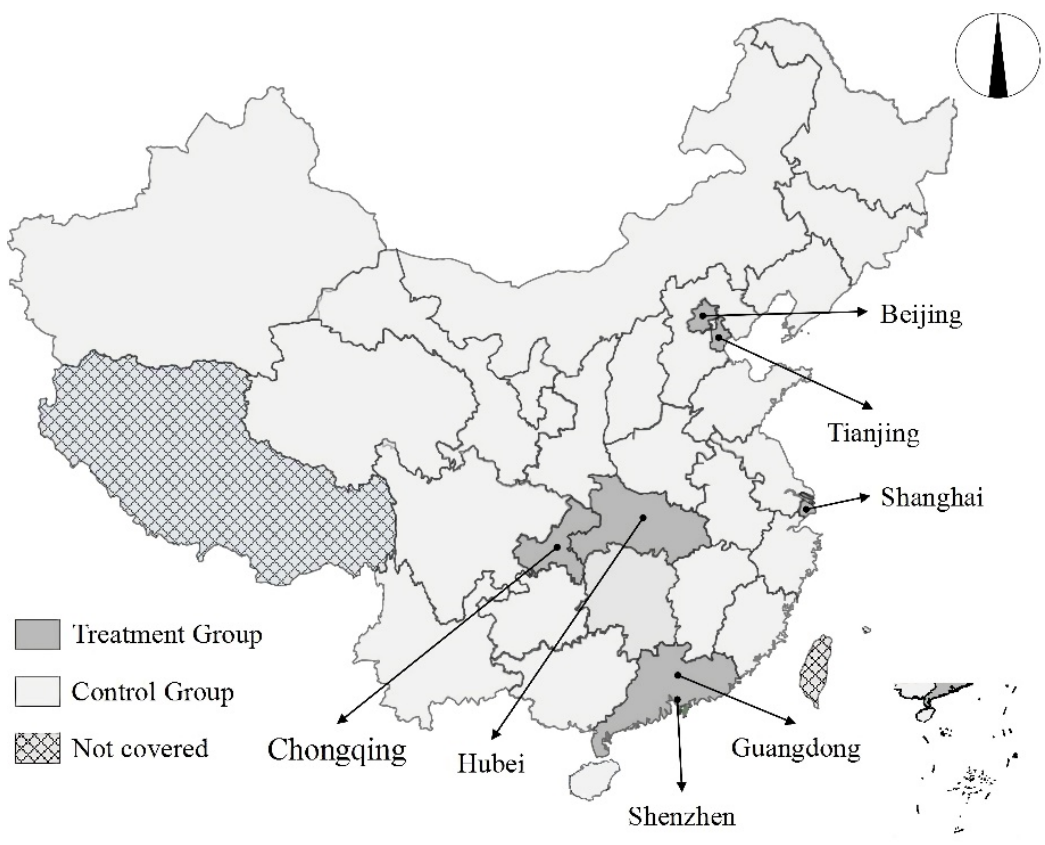

Figure 2. Distribution of CETS pilot provinces.

\subsection{Entropy Method}

The entropy method, which is a comprehensive indicator method, has the characteristic of giving weights through the deviation between variables. When the uncertainty between variables is greater, the degree of deviation is also greater, indicating that it contains more valid information and it is therefore assigned a higher weight. Conversely, variables that contain less valid information are naturally given less weight. Based on this characteristic, the entropy method has the advantage of alleviating information overlap among variables and giving weights objectively. In addition, the weight of each secondary indicator reflects its contribution to the composite indicator, which allows scholars to further explore the impact of the refined indicators [65]. Referring to the method of Tang et al. [66], the basic steps of the entropy method that was used in this paper are as follows. We used MATLAB R2016a software to realize the measurement.

Step 1: Suppose $i$ is region $i, b$ is indicator $\mathrm{b}(1 \leq b \leq k)$, and $t$ is period $\mathrm{t}$. The term $x_{i, b, t}$ is the element of the $b$ th indicator in period $t$ of region $i$. We derived the normalized form of $x_{i, b, t}$ by using Equation (3).

$$
x_{i, b, t}^{\prime}=\frac{x_{i, b, t}-\min \left|x_{i, b, t}\right|}{\max \left|x_{i, b, t}\right|-\min \left|x_{i, b, t}\right|},
$$

Step 2: Information entropy was assumed to be $E_{b, t}$, which reflects the intensity of the amount of information contained in the bth indicator in period $t$ in all regions. The number 30 refers to the 30 provinces and municipalities directly under the central government that were involved in this study. The specific equation is as follows.

$$
\begin{gathered}
E_{b, t}=-\ln (30)^{-1} \sum_{i=1}^{30}\left(M_{i, b, t}^{\prime}\right) \ln \left(M_{i ., b, t}^{\prime}\right) \\
\text { s.t. } M_{i ., b, t}^{\prime}=\frac{x_{i, b, t}^{\prime}}{\sum_{i=1}^{30} x_{i, b, t}^{\prime}},
\end{gathered}
$$

Step 3: The weight of the $b$ th indicator in period $t\left(W_{b, t}\right)$ was calculated. The term $k$ is the total number of indicators.

$$
W_{b, t}=\frac{1-E_{b, t}}{k-\sum E_{b, t}}
$$




\subsection{Data}

\subsubsection{Explained Variables}

LUT can refer to the process of land use pattern changes that occur over time corresponding to the transition between economic and social development stages, which are inseparable from economic activities. In this paper, the change tendency of LUT is measured in three dimensions: the economic, environmental and Porter effects of the CETS. The construction of the indicators for these three dimensions of LUT is described below (Table 1).

Table 1. Indicators evaluation system of LUTs and weight distribution over the years.

\begin{tabular}{|c|c|c|c|c|c|c|c|c|c|}
\hline LUT & Description & Unit & 2011 & 2012 & 2013 & 2014 & 2015 & 2016 & 2017 \\
\hline \multirow{4}{*}{$\begin{array}{l}\text { Economic level } \\
\text { tendency of LUT }\end{array}$} & Per capita GDP (PGDP) & Yuan/person & $16.14 \%$ & $15.82 \%$ & $17.37 \%$ & $10.91 \%$ & $14.90 \%$ & $15.55 \%$ & $13.24 \%$ \\
\hline & $\begin{array}{l}\text { GDP per unit of land area } \\
\text { (LGDP) }\end{array}$ & $\begin{array}{c}\text { Million } \\
\text { yuan } / \mathrm{km}^{2}\end{array}$ & $56.03 \%$ & $53.67 \%$ & $53.21 \%$ & $69.72 \%$ & $46.61 \%$ & $50.82 \%$ & $42.58 \%$ \\
\hline & $\begin{array}{l}\text { Added value from } \\
\text { secondary industry } \\
\text { generated by power } \\
\text { consumption per unit of } \\
\text { industrial production (SIPC) }\end{array}$ & $\begin{array}{c}10,000 \\
\text { yuan/kWh }\end{array}$ & $11.98 \%$ & $14.47 \%$ & $11.58 \%$ & $7.21 \%$ & $16.96 \%$ & $16.38 \%$ & $28.32 \%$ \\
\hline & $\begin{array}{l}\text { Proportion of added value } \\
\text { fromtertiary industry (PTI) }\end{array}$ & $\%$ & $15.85 \%$ & $16.04 \%$ & $17.84 \%$ & $12.16 \%$ & $21.53 \%$ & $17.25 \%$ & $15.86 \%$ \\
\hline \multirow{2}{*}{$\begin{array}{c}\text { Green } \\
\text { development } \\
\text { tendency of LUT }\end{array}$} & $\mathrm{CO}_{2}$ emissions (CE) & $\begin{array}{l}\text { Million } \\
\text { Tons }\end{array}$ & $53.78 \%$ & $53.12 \%$ & $43.51 \%$ & $52.65 \%$ & $52.27 \%$ & $49.01 \%$ & $53.07 \%$ \\
\hline & $\mathrm{SO}_{2}$ emissions (SE) & Tons & $46.22 \%$ & $46.88 \%$ & $56.49 \%$ & $47.35 \%$ & $47.73 \%$ & $50.99 \%$ & $46.93 \%$ \\
\hline \multirow{4}{*}{$\begin{array}{l}\text { Economic quality } \\
\text { tendency of LUT }\end{array}$} & $\begin{array}{l}\text { Full-time equivalent of R \& } \\
\text { D personnel (RDFE) }\end{array}$ & Man year & $31.43 \%$ & $11.18 \%$ & $37.02 \%$ & $15.08 \%$ & $10.99 \%$ & $37.30 \%$ & $17.02 \%$ \\
\hline & $\begin{array}{c}\text { Internal expenditure of R \& } \\
\text { D funds (RDIE) }\end{array}$ & 10,000 Yuan & $23.94 \%$ & $31.24 \%$ & $21.98 \%$ & $23.90 \%$ & $29.24 \%$ & $24.20 \%$ & $30.23 \%$ \\
\hline & $\begin{array}{l}\text { Number of non-industrial } \\
\text { design patent applications } \\
\text { per capita (NDPA) }\end{array}$ & $\begin{array}{l}\text { Items } / 10,000 \\
\text { people }\end{array}$ & $31.42 \%$ & $38.79 \%$ & $28.04 \%$ & $31.88 \%$ & $38.62 \%$ & $27.92 \%$ & $33.40 \%$ \\
\hline & $\begin{array}{l}\text { Proportion of science and } \\
\text { technology in general public } \\
\text { budget expenditure (PSTE) }\end{array}$ & $\%$ & $13.22 \%$ & $18.79 \%$ & $12.95 \%$ & $29.14 \%$ & $21.15 \%$ & $10.58 \%$ & $19.36 \%$ \\
\hline
\end{tabular}

1. The economic level reflects the impact of the CETS policy on the economic development level of the pilot region. After the implementation of the CETS, it was noted that the output of pilot enterprises was negatively affected in the short term. This was due to the difficulty experienced by enterprises in attempting to quickly adjusting their production patterns in the short term. Considering the contradiction between the cost and liquidity of enterprises, the innovative $\mathrm{R} \& \mathrm{D}$ behavior of enterprises may also slow their operation, thus leading to a decline in the economic level in the region. In the long run, the production efficiency of enterprises in the region was improved and the products were more competitive, which may lead to a rise in the economic level in the region. In any case, the implementation of the CETS policy changed the economic level of land use in the region. The economic level consists of four secondary indicators: per capita GDP, GDP per unit of land area, added value from secondary industry that is generated by power, and proportion of added value from tertiary industry. (I) Per capita GDP (PGDP), which directly reflects the economic level within a region but is influenced by the size of the population [67], is divided by the number of residents (i.e., the population) in order to limit this effect. (II) Regions with high economic levels should be able to utilize each piece of land more fully in 
order to generate more economic returns. Although the type of land is closely related to its economic value, the trend of enhancing the economic return per unit of land output was constant. At the same time, the entropy method can better mitigate the impact of the size of the indicators' value. Therefore, in this paper, GDP divided by land area, i.e., GDP per unit of land area (LGDP), was used as one of the indicators in order to reflect the economic level of a region. (III) The added value from secondary industry that is generated by power consumption per unit of industrial production (SIPC) reflects the economic benefits that can be generated per unit of energy and also reflects the economic activities that are undertaken by enterprises in the region in response to the CETS. (IV) The proportion of added value from tertiary industry (PIT) is the ratio of tertiary industry to total industry value added. The value added from industry was reduced because CETS may induce some highly polluting and low-profit enterprises to leave the market. At the same time, CETS will encourage some firms to flow into the tertiary industry with low pollution and high profit margins, thus causing the PIT to increase [68,69].

2. Green development reflects the environmental improvement in the pilot area resulting from the CETS policy. After the implementation of the CETS, due to the government's regulatory actions, enterprises in the pilot areas were bound to reduce their pollution emissions and the final result was the transition of land use in the region towards green development. The green development dimension consists of two secondary indicators: $\mathrm{CO}_{2}$ emissions and $\mathrm{SO}_{2}$ emissions. (I) $\mathrm{CO}_{2}$ emissions (CE) are the pollutant emissions that the CETS policy directly interferes with. A high concentration of CE may induce greenhouse effects and cause a series of environmental problems. Meanwhile, LUT is closely related to the carbon cycle and greenhouse gases [25]. Therefore, the CE was chosen as an indicator to measure the green development tendency (GDT) of LUT in this paper. (II) $\mathrm{SO}_{2}$ emissions (SE) often accompany CE emissions in the industrial production process. For example, in the process of coal combustion, not only is a large amount of CE produced, but a large amount of SE is produced too. Therefore, in this paper, SE was chosen as an indicator of the GDT of LUT.

3. Economic quality reflects the possible Porter effects of the CETS policy on the innovation incentives of the firms that were included within the pilot. After the implementation of CETS, enterprises moved towards energy saving and emission reduction and output efficiency in order to reduce emission costs, thus transitioning the land use within the region towards high-quality economic development. Economic quality consists of the full-time equivalent of $R$ \& D personnel, internal expenditure of $R$ \& D funds, number of non-industrial design patent applications per capita, and proportion of science and technology in the general public. (I) The full-time equivalent of R \& $\mathrm{D}$ personnel (RDFE) reflects the level of innovative $\mathrm{R} \& \mathrm{D}$ efforts in a region. The RDFE will increase when the firms in the region are influenced by the CETS and actively innovate $R$ \& D. (II) Internal expenditure of $R$ \& D funds (RDIE) reflects a region's emphasis on innovative $\mathrm{R} \& \mathrm{D}$. When firms in the region are influenced by CETS and initiate innovative $R \& D$, they will increase their material investment (that is, RDIE will be higher), which will drive economic growth [70]. (III) The number of non-industrial design patent applications per capita (NDPA) reflects the level of innovation in a region [71]. When a pilot region is subject to CETS and starts innovation activities, the end result is a significant increase in the number of utility model patent and invention patent applications (both are collectively referred to as nonindustrial design patents). (IV) The proportion of science and technology spending in the general public budget expenditure (PSTE) reflects the importance that local governments place on local innovation development. When regions are affected by the CETS, local officials will enact a series of targeted incentives in order to guide the economic activities of local enterprises, improving their own performance and catering to the policy requirements [72]. 
The core explanatory variable in this study is the interaction term of the treatment group dummy variable and the treatment period dummy variable $\left(\right.$ Treat $_{i} \times$ Post $\left._{t}\right)$. According to the previous analysis, Treat $t_{i} \times$ Post $_{t}$ needs to reflect whether region $i$ in period $t$ is a pilot region that has implemented CETS. When Treati $\times \operatorname{Postt}=1$, this indicates that region $i$ is a pilot region and period $t$ occurred in the year of the CETS policy's implementation or after. Otherwise, Treat $_{i} \times$ Post $_{t}=0$. Equation (6) is the constructive equation of Treat $_{i} \times$ Post $_{t}$.

\subsubsection{Explanatory Variable}

The core explanatory variable in this study is the interaction term of the treatment group dummy variable and the treatment period dummy variable $\left(\right.$ Treat $_{i} \times$ Post $\left._{t}\right)$. According to the previous analysis, Treat ${ }_{i} \times$ Post $_{t}$ needed to reflect whether region $\mathrm{i}$ in period $\mathrm{t}$ was a pilot region that had implemented the CETS. When Treat ${ }_{i} \times$ Post $_{t}=1$, this indicates that region $i$ was a pilot region and period $t$ occurred in the year of the CETS policy's implementation or after. Otherwise, Treat $_{i} \times$ Post $_{t}=0$. Equation (6) is the constructive equation of Treat $_{i} \times$ Post $_{t}$.

$$
\text { Treat }_{i} \times \text { Post }_{t}=\left\{\begin{array}{l}
1, i \text { is the pilot area and CETS has been implemented in period } t \\
0, \text { otherwise }
\end{array}\right. \text {, }
$$

\subsubsection{Data Sources}

This study examined 30 provinces and municipalities that were directly under the control of the central government in China from 2011 to 2017. Considering data integrity and statistical caliber, the Tibet Autonomous Region, Hong Kong and Macao Special Administrative Regions, and Taiwan were excluded from the scope of the study. The primary data that were used in this study were mainly sourced from the China Statistical Yearbook, China Environmental Statistical Yearbook, provincial statistical yearbooks, and the China Research Database Service Platform (CNRDS). The data on carbon emissions were obtained from the China Emission Accounts and Datasets (CEADs), the measurement of which can be found in Shan et al. [73,74]. Table 2 reports the basic information of all of the variables that are involved in this study.

Table 2. Descriptive statistics of all variables.

\begin{tabular}{cccccc}
\hline Variable & Obs. & Mean & Std. & Min. & Max. \\
\hline PGDP & 210 & 49969.69 & 22922.91 & 16480 & 118198 \\
LGDP & 210 & 53.71947 & 262.2062 & 0.1900693 & 3677.705 \\
SIPC & 210 & 21.90853 & 21.03051 & 0.2456184 & 251.7656 \\
PTI & 210 & 44.61187 & 9.457079 & 29.7 & 80.5562 \\
CE & 210 & 310.3055 & 187.5209 & 35.18979 & 768.3882 \\
SE & 210 & 514383 & 473367.8 & 1076 & 2716452 \\
RDFE & 210 & 92788.18 & 98869.35 & 2501 & 543438 \\
RDIE & 210 & 4128070 & 4557944 & 103717 & 20400000 \\
NDPA & 210 & 10.74831 & 12.5819 & 0.5088028 & 68.12073 \\
PSTE & 210 & 0.384685 & 0.2127455 & 0.1389526 & 1.430969 \\
ELT & 210 & 3.333333 & 4.885271 & 0.338749 & 52.92379 \\
GDT & 210 & 3.333333 & 2.188491 & 0.0170493 & 10.53953 \\
EQT & 210 & 3.333333 & 2.601652 & 0.2372233 & 10.72221 \\
Treat & & 0.2 & 0.4009558 & 0 & 1 \\
Post $_{2013}$ & 210 & 0.7142857 & 0.4528334 & 0 & 1 \\
Post $_{2014}$ & 210 & 0.5714286 & 0.4960542 & 0 & 1 \\
\hline
\end{tabular}

\section{Results}

\subsection{Baseline Regression Results}

This paper examines the effects of the causal relationships between the CETS on economic level tendency (ELT), green development tendency (GDT) and economic quality 
tendency (EQT) of LUT through the DID model of Equation (2). Since the six pilot provinces of CETS were opened one by one between June 2013 and June 2014 and there were time lags in the economic quality tendency and economic level tendency of LUT, we took 2013 and 2014 as the start-up times of the CETS policies. This paper used the Stata 15 software computing model. Table 3 reports the baseline regression results.

Table 3. Baseline regression results for the three dimensions of LUT.

\begin{tabular}{|c|c|c|c|c|c|c|}
\hline & \multicolumn{2}{|c|}{ (I) } & \multicolumn{2}{|c|}{ (II) } & \multicolumn{2}{|c|}{ (III) } \\
\hline & ELT & ELT & GDT & GDT & EQT & EQT \\
\hline Treat $_{i} \times$ Post $_{2013}$ & $\begin{array}{c}-2.1619 * \\
(-1.96)\end{array}$ & - & $\begin{array}{c}-0.3088^{* * *} \\
(-3.91)\end{array}$ & - & $\begin{array}{l}0.0523 \\
(0.10)\end{array}$ & - \\
\hline Treat $_{i} \times$ Post $_{2014}$ & - & $\begin{array}{c}-2.6208^{* *} \\
(-2.04)\end{array}$ & - & $\begin{array}{l}-0.1645 \\
(-1.51)\end{array}$ & - & $\begin{array}{l}0.3416 \\
(1.09)\end{array}$ \\
\hline $\begin{array}{c}\text { Year } \\
\text { Fixed Effects }\end{array}$ & YES & YES & YES & YES & YES & YES \\
\hline $\begin{array}{c}\text { Province } \\
\text { Fixed Effects }\end{array}$ & YES & YES & YES & YES & YES & YES \\
\hline $\mathrm{R}^{2}$ & 0.2380 & 0.2380 & 0.2751 & 0.2751 & 0.2655 & 0.2655 \\
\hline Obs & 210 & 210 & 210 & 210 & 210 & 210 \\
\hline
\end{tabular}

The coefficient of the Treat ${ }_{i} \times$ Post $_{2013}$ term in the first column of Table 3(I) is -2.1619 , which passes the $10 \%$ significance test. Meanwhile, the coefficient of the Treat $_{i} \times$ Post $_{2014}$ term in the second column of Table $3(\mathrm{I})$ is -2.6208 , which passes the significance test at the $5 \%$ level of significance. This indicates that the CETS significantly reduced the ELT of the pilot provinces, regardless of whether 2013 or 2014 was used as the start of the CETS policy (Therefore, H1 holds). Meanwhile, by comparing the magnitude of the $\mathrm{t}$-values and the magnitude of the coefficients, it can be tentatively determined that the CETS policy had a greater impact on ELT in 2014 and after.

The coefficient of the Treat $_{i} \times$ Post $_{2013}$ term in the first column of Table 3(II) is -0.3088 , significant at the 1\% significance level, indicating that the GDT of the pilot regions declined with the implementation of the CETS policy (Therefore, H2 holds). Since GDT is a negative indicator, and the lower the GDT, the lower the environmental pollution, the CETS improved environmental pollution in the pilot areas. The coefficient of the Treat ${ }_{i} \times$ Post $_{2014}$ term in the second column of Table 3(II) does not pass the $10 \%$ significance level test; although it is also negative, indicating that the CETS cannot significantly improve environmental pollution if 2014 is used as the start of the CETS policy. This indirectly reflects that the impact of the CETS policy on green development started in 2013.

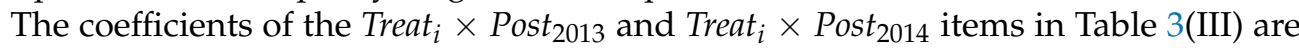
0.0523 and 0.3416 , respectively, and consistent with our expectations. However, both scores failed the significance test at the $10 \%$ significance level, indicating that there is no significant causal relationship between CETS and the improvement in economic quality tendency in the pilot regions, regardless of whether 2013 or 2014 is used as the starting point for the implementation of the CETS policy (Therefore, H3 does not hold).

\subsection{Parallel Trend Assumption Test}

Parallel trend assumption is a necessary condition for the validity of the DID model's conclusions. It assumes that the treatment and control groups must be comparable and consistent before the policy or event occurs. Accordingly, this paper designed the parallel trend assumption strategy: before the CETS policy was implemented, the treatment and control groups had basically similar trends of change; but after the CETS policy was implemented, a significant difference emerged between the treatment group and the control 
group due to the impact of the policy shock. In this paper, the event analysis framework was used to examine this strategy. The regression equation is shown in Equation (7).

$$
\ln L U T_{i, t}=\sum_{\tau=2011}^{2017} \beta_{\tau} \text { Treat }_{i} \times \operatorname{Dum}_{\tau}+\mu_{i}+\gamma_{t}+\varepsilon_{i, t}
$$

where $D u m_{\tau}$ is the year dummy variable and $\beta_{\tau}$ is the main examined coefficient of Equation (7). If none of the $\beta$ values corresponding to the pre-CETS policy implementation are significant, while most of the $\beta$ values corresponding to the post-CETS implementation pass at least the $10 \%$ significance test, then the model's results satisfy the parallel trend assumption (and vice versa, which would indicating that the study's results are not valid).

The results of the baseline regressions that are described above show that the CETS policy with 2013 as the start-up time had a significant effect on ELT and GDT, while the CETS with 2014 as the start-up time only had a significant effect on ELT. Therefore, this section performs parallel trend assumption tests for each of the three cases mentioned above. Figure 3 plots the $\beta_{\tau}$ estimations and their $90 \%$ confidence intervals for each year.

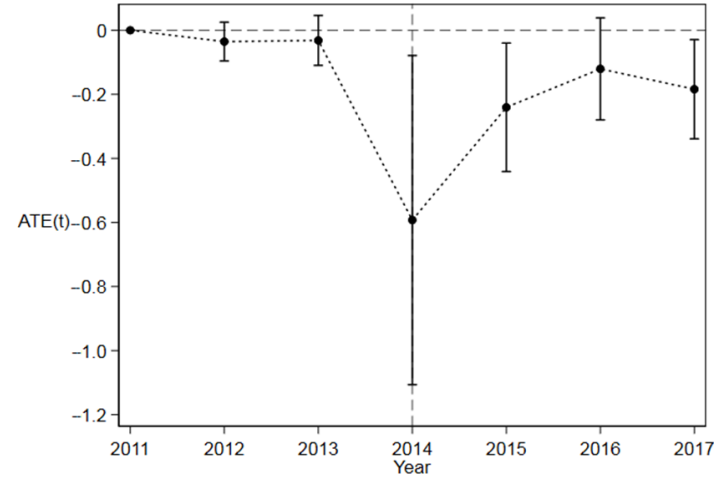

(a)

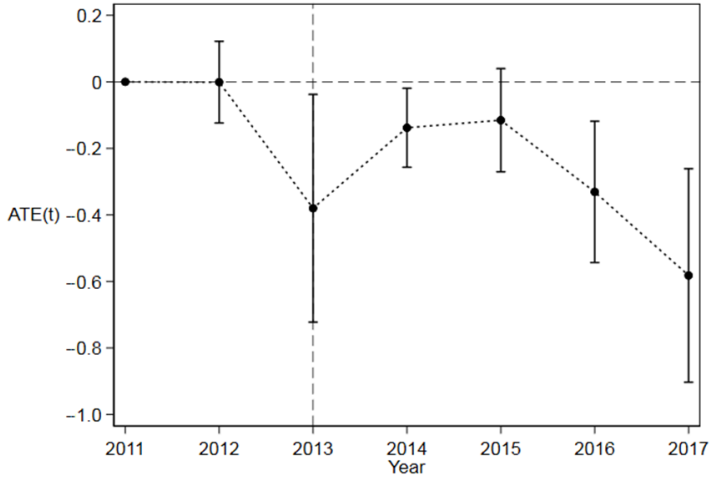

(b)

Figure 3. Parallel trend assumption tests. (a) CETS (starting in 2014) for the ELT; (b) CETS (starting in 2013) for the GDT.

Figure 3a shows the parallel trend test of CETS (with 2014 as the start time) for ELT. It can be observed that the $\beta$ values corresponding to 2011, 2012 and 2013 fail the $10 \%$ significance test, while the $\beta$ values corresponding to 2014, 2015 and 2017 pass the significance test at least the $10 \%$ significance level. While in 2016 , the $\beta$ values were not significant, it is possible to conclude that, overall, the CETS significantly reduced the ELT in the pilot provinces and this finding is valid. In addition, the result showing that the CETS (with 2013 as the start time) had a significant negative effect on ELT does not pass the parallel trend assumption test and therefore is not included in Figure 3.

Figure 3b shows the parallel trend test of the CETS (with 2013 as the start time) for GDT. The $\beta$ values corresponding to both 2011 and 2012 do not pass the $10 \%$ significance test, while the $\beta$ values corresponding to 2013, 2014, 2016 and 2017 pass the significance test at least the $10 \%$ level of significance. Although for 2015 the $\beta$ values were not significant, it seems that the conclusion that CETS can improve environmental pollution in the pilot regions as a whole is valid.

\section{Discussion}

\subsection{Discussion of the Combination of the Empirical Results and the Entropy Method Results}

This sub-section combines the regression results of Section 3 with the weight changes of each secondary indicator as reported in Table 1. 
1. Hypothesis 1 of this paper holds - that is, the implementation of the CETS was found to promote the land use transition in the pilot areas toward economic development, but this had a negative impact on the economy in the short term. The implementation of the CETS significantly reduced the economic growth trend in 2014 and in the years after. This suggests that, in order to reduce pollution emissions, firms may choose to reduce production or not to produce, while the demand for cash flow from innovative $\mathrm{R} \& \mathrm{D}$ practices will also drag down firms' production, thus reducing the total output in the region. Based on the trend of weight changes in the secondary indicators, per capita GDP (PGDP), GDP per unit of land area (LGDP), added value from secondary industry generated by power consumption per unit of industrial production (SIPC) and the proportion of added value from tertiary industry (PTI) in Table 1, it is clear that LGDP had the highest weight and remained above $50 \%$ for many years. This indicates that many regions with high output per unit of land, especially the pilot regions, have started to reduce production, indirectly reflecting that past output may have been caused by high-pollution industries. At the same time, it is noted that the weight value of LGDP has decreased significantly since 2014, while the weight value of SIPC has increased significantly, which, on the one hand, reflects the influence of CETS and, on the other hand, indicates that enterprises in the pilot areas have started to focus on production efficiency and obtain more economic benefits with less energy consumption.

2. Hypothesis 2 of this paper holds, i.e., the implementation of the CETS promoted the LUT in pilot areas toward green development. The implementation of the CETS has been effective in reducing $\mathrm{CO}_{2}$ emissions (CE) and $\mathrm{SO}_{2}$ emissions (SE) in the pilot areas since 2013. This shows that the emitting companies have effectively reduced their related emissions and shifted towards a green development strategy. At the same time, according to the weights of CE and SE in Table 1, the values of the two weights are comparable and do not change significantly over time. This indicates that the discrete changes of the two are roughly the same, which is consistent with the previous conclusion that carbon dioxide and sulfur dioxide emissions are consistent, indirectly reflecting that the CETS also has an emission reduction effect on non-carbon pollution.

3. Hypothesis 3 of this paper does not hold, i.e., the implementation of the CETS was not found to promote land use transition in the pilot areas toward high-quality economic development. The empirical results show that there was no clear causal relationship between the implementation of CETS policy and the improvement of economic quality in the pilot areas. That is, at least during the period 2013-2017, CETS could not significantly improve the pilot areas' full-time equivalent of R \& D personnel (RDFE), internal expenditure of R \& D funds (RDIE), number of non-industrial design patent applications per capita (NDPA) and proportion of science and technology spending in the general public budget expenditure (PSTE). Meanwhile, the weights of RDFE, RDIE, NDPA and PSTE, shown in Table 1, did not show a clear trend change over time. This reflects that it is currently difficult for the CETS to effectively contribute to high-quality economic development and form an economic-environmental win-win situation.

\subsection{Spatio-Temporal Analysis of LUTs}

Based on the above conclusions and discussions, this sub-section presents the spatiotemporal evolutionary trends of ELT and GDT data on the provincial-level regional distribution map of China (Figure 4) through the use of ArcMap software. In order to better demonstrate the trends of the variables, this study processed the ELT and GDT data as follows (taking ELT as an example).

Step 1: Taking 2013 as the threshold, the average of ELT in 2011 and 2012 was taken as the proxy variable Pre $_{i}$ for ELT before the policy shock. Similarly, the average of ELT from 2013 to 2017 was taken as the proxy variable $\operatorname{Pos}_{i}$ for ELT after the policy shock. 
Step 2: We calculated the Change $e_{i}$ variable, which reflects the degree and direction of change in ELT before and after the policy shock. Change $e_{i}=$ Pos $_{i}$-Pre $e_{i}-$ if the sign of Changei is negative, the ELT decreases after the CETS policy shock in region $i$.

Step 3: The Change $e_{i}$ variables were input into the distribution map of provincial areas in China (Figure 4a) through the ArcMap software and, at the same time, the eight areas with the most reduced tendencies were specifically marked out, representing the eight provinces with the most reduced economic values before and after the CETS policy was implemented.

We undertook the same measures for the GDT data in order to obtain Figure 4b. If the sign of the Change $e_{i}$ variable is negative, this means that the GDT of region i decreased after the CETS policy shock and the environmental pollution level in region i was improved.

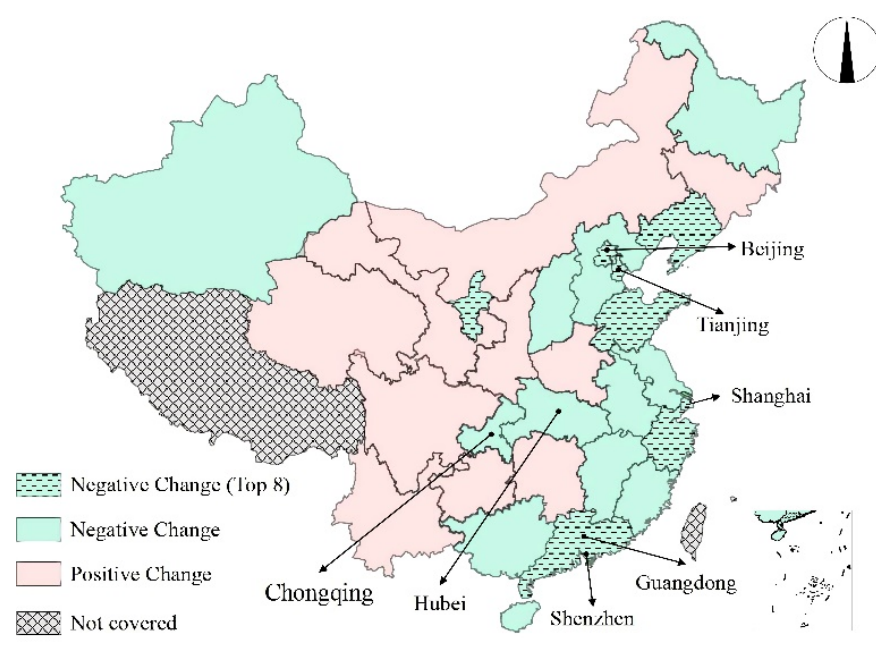

(a)

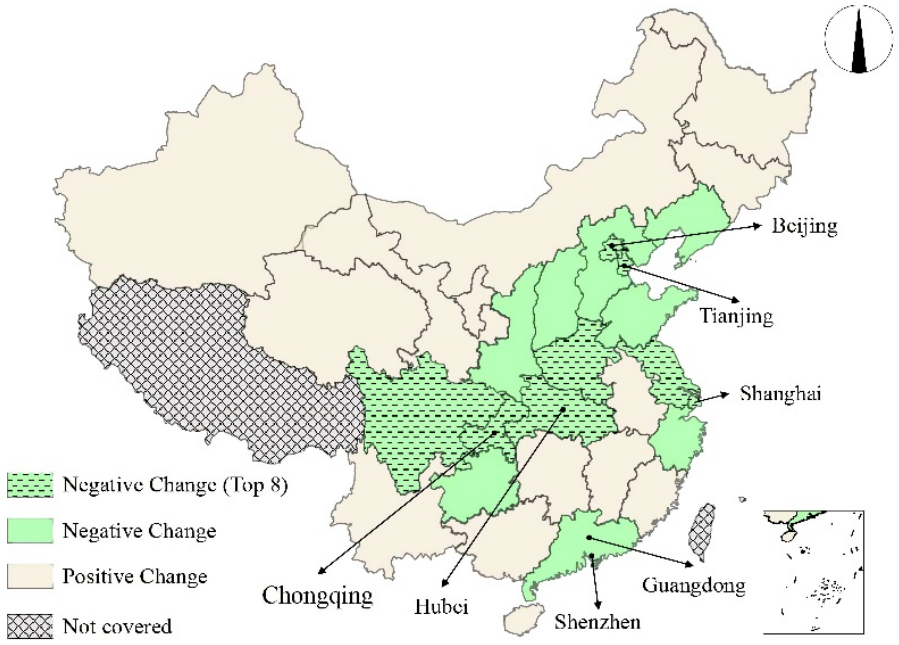

(b)

Figure 4. Spatio-temporal evolution of LUT. (a) Economic level tendency; (b) green development tendency.

According to Figure 4a, the economic level decreased in 20 provinces before and after the CETS policy took effect. Six CETS pilot regions declined economically, with Beijing, Tianjin, Shanghai, and Guangdong being among the top eight provinces in terms of decline. These four provinces and cities have higher economic levels and are therefore more affected by the CETS. Similarly, it can be found that the provinces with declining ELTs are mainly concentrated in the eastern coastal region and its adjacent areas and there are clustering characteristics.

Figure $4 \mathrm{~b}$, shows that there were 14 provinces with improved environmental pollution before and after the CETS policy took effect. Six CETS pilot areas showed improved environments, with Beijing, Tianjin, Shanghai, Hubei, and Chongqing in the top eight provinces in terms of change. This indicates that, although there are non-pilot areas where the environment improved, the degree of improvement was overall less than that in the pilot areas affected by the CETS policy. In addition, the environmental improvement provinces are mainly concentrated in the eastern and central regions and are adjacent to each other, with clustering characteristics.

\subsection{Policy Recommendations}

This paper has obtained the following conclusions: (1) Under the influence of the CETS, land use in the pilot area was transitioned in the direction of economic level reduction in the short term. However, during this period, the efficiency of industrial energy use was improved. This economic disincentive effect had spatial clustering characteristics and was mainly concentrated in the coastal areas of southeast China and economically developed regions. (2) Under the influence of the CETS, the emissions of $\mathrm{CO}_{2}$ and $\mathrm{SO}_{2}$ in the pilot areas significantly decreased and land use transitioned towards green development. This 
emission reduction effect had spatial clustering characteristics and was mainly concentrated in the central region of China. (3) Under the influence of the CETS, land use in the pilot regions did not transition towards high-quality economic development.

Accordingly, the policy guidance obtained from this paper is as follows:

The implementation of the CETS has been successful for China and its benefits outweigh its disadvantages. Under the influence of the CETS, $\mathrm{CO}_{2}$ and $\mathrm{SO}_{2}$ emissions have been significantly reduced and the environmental effects of these reductions have been practically realized. At the same time, although the CETS has inhibited the economic development of the pilot regions, the pilot enterprises are independently improving their energy output per unit. This essentially optimizes the economic development, eliminates high-pollution and low-efficiency enterprises, and encourages the enterprises to transition towards innovative development. The most important deficiency during the implementation of the CETS is that it did not effectively increase the innovation output of the pilot enterprises, which is not in line with the goal of "building China into an innovation power" and is not conducive to the promotion of China's sustainable development path.

Author Contributions: Conceptualization, Y.T., Y.Y. and H.X.; methodology, Y.Y. and H.X.; software, Y.Y.; formal analysis, Y.Y. and H.X.; writing-original draft preparation, Y.Y.; writing-review and editing, Y.T. and H.X. All authors have read and agreed to the published version of the manuscript.

Funding: This research was funded by [the National Natural Science Foundation of China] grant number [No. 71072066], and [Sichuan University] grant number [No. SKGT201602 and No. 2019hhf-14].

Data Availability Statement: Raw data is available from a paid database, please contact the corresponding author if needed.

Conflicts of Interest: The authors declare no conflict of interest.

\section{References}

1. Chen, G.; Deng, Y.Q. Chinese-style Decentralization and Environmental Pollution: An Empirical Study of Air Quality Based on Provincial Panel Data in China. J. Xiamen Univ. 2015, 4, 110-120.

2. Stern, N. A Blueprint for a Safer Planet: How to Manage Climate Change and Create a New Era of Progress and Prosperity; Random House: New York, NY, USA, 2009.

3. Tang, L.; Wang, H.; Li, L.; Yang, K.; Mi, Z. Quantitative modELT in emission trading system research: A literature review. Renew. Sustain. Energy Rev. 2020, 132, 110052. [CrossRef]

4. Cao, J.; Karplus, V.J. Firm-level determinants of energy and carbon intensity in China. Energy Policy 2014, 75, 167-178. [CrossRef]

5. Ba, F.; Thiers, P.R.; Liu, Y. The evolution of China's emission trading mechanisms: From international offset market to domestic Emission Trading Scheme. Environ. Plan. C Politics Space 2018, 36, 1214-1233. [CrossRef]

6. Lambin, E.F.; Meyfroidt, P. Land use transition: Socio-ecological feedback versus socio-economic change. Land Use Policy 2010, 27, 108-118. [CrossRef]

7. Long, H.L. Land use transitions and land management. Geogr. Res. 2015, 34, 1607-1618. [CrossRef]

8. Grainger, A. The Future Role of the Tropical Rain Forests in the World Forest Economy; University of Oxford: Oxford, UK, 1986.

9. Grainger, A. The forest transition: An alternative approach. Area 1995, 27, 242-251.

10. Wen, Y.; Zhang, Z.; Liang, D.; Xu, Z. Rural residential land transition in the Beijing-Tianjin-Hebei region: Spatial-temporal patterns and policy implications. Land Use Policy 2020, 96, 104700. [CrossRef]

11. Long, H.; Heilig, G.K.; Li, X.; Zhang, M. Socio-economic development and land-use change: Analysis of rural housing land transition in the Transect of the Yangtse River, China. Land Use Policy 2007, 24, 141-153. [CrossRef]

12. Liu, J.; Kuang, W.; Zhang, Z.; Xu, X.; Qin, Y.; Ning, J.; Zhou, W.; Zhang, S.; Li, R.; Yan, C.; et al. Spatiotemporal characteristics, patterns, and causes of land-use changes in China since the late 1980s. J. Geogr. Sci. 2014, 24, 195-210. [CrossRef]

13. Ning, J.; Liu, J.; Kuang, W.; Xu, X.; Zhang, S.; Yan, C.; Li, R.; Wu, S.; Hu, Y.; Du, G.; et al. Spatio-temporal patterns and characteristics of land-use change in China during 2010-2015. Acta Geogr. Sin. 2018, 28, 547-561.

14. Chen, W.; Zhao, H.; Li, J.; Zhu, L.; Wang, Z.; Zeng, J. Land use transitions and the associated impacts on ecosystem services in the Middle Reaches of the Yangtze River Economic Belt in China based on the geo-informatic Tupu method. Sci. Total Environ. 2020, 701, 134690. [CrossRef]

15. Fang, C. Spatial Organization Pattern and High-Quality Development of Urban Agglomeration in the Yellow River Basin. Econ. Geogr. 2020, 40, 1-8.

16. Sun, P.; Xu, Y.; Wang, S. Terrain gradient effect analysis of land use change in poverty area around Beijing and Tianjin. Trans. Chin. Soc. Agric. Eng. 2014, 30, 277-288. 
17. Wang, C.; Wang, Y.; Wang, R.; Zheng, P. Modeling and evaluating land-use/land-cover change for urban planning and sustainability: A case study of Dongying city, China. J. Clean Prod. 2018, 172, 1529-1534. [CrossRef]

18. Liu, J.; Wang, P.; Li, J.; Xu, J.; Liu, X. An Algorithm for Land-Use Pattern Index and Its Application. Geogr. Geo-Inf. Sci. 2009, 25, 107-109.

19. Mather, A.S.; Fairbairn, J.; Needle, C.L. The course and drivers of the forest transition: The case of France. J. Rural Stud. 1999, 15, 65-90. [CrossRef]

20. Mather, A.S.; Needle, C.L. The forest transition: A theoretical basis. Area 1998, 30, 117-124. [CrossRef]

21. Tuan, Y.F. Geography, phenomenology and the study of human nature. Can. Geogr. 1971, 15, 181-192. [CrossRef]

22. Long, H.L. Land Use Transitions and Rural Restructuring in China; Springer: Singapore, 2020.

23. Xu, J.; Sharma, R.; Fang, J.; Xu, Y. Critical linkages between land-use transition and human health in the Himalayan region. Environ. Int. 2008, 34, 239-247. [CrossRef] [PubMed]

24. Van Vliet, J.; de Groot, H.L.F.; Rietveld, P.; Verburg, P.H. Manifestations and Underlying Drivers of Agricultural Land Use Change in Europe. Landsc. Urban Plan. 2015, 133, 24-36. [CrossRef]

25. Houghton, R.A.; Nassikas, A.A. Global and regional fluxes of carbon from land use and land cover change 1850-2015. Glob. Biogeochem. Cycles 2017, 31, 456-472. [CrossRef]

26. Quintero-Angel, M.; Coles, A.; Duque-Nivia, A.A. A historical perspective of landscape appropriation and land use transitions in the Colombian South Pacific. Ecol. Econ. 2021, 181, 106901. [CrossRef]

27. Liu, J.; Zhang, Z.; Xu, X.; Kuang, W.; Zhou, W.; Zhang, S.; Li, R.; Yan, C.; Yu, D.; Wu, S.; et al. Spatial patterns and driving forces of land use change in China during the early 21st century. J. Geogr. Sci. 2010, 20, 483-494. [CrossRef]

28. Liu, Y.; Long, H. Land use transitions and their dynamic mechanism: The case of the Huang-Huai-Hai Plain. J. Geogr. Sci. 2016, 26, 515-530. [CrossRef]

29. Qu, Y.; Jiang, G.; Li, Z.; Tian, Y.; Wei, S. Understanding rural land use transition and regional consolidation implications in China. Land Use Policy 2019, 82, 742-753. [CrossRef]

30. Ge, D.; Long, H.; Zhang, Y.; Ma, L.; Li, T. Farmland transition and its influences on grain production in China. Land Use Policy 2018, 70, 94-105. [CrossRef]

31. Nizalov, D.; Thornsbury, S.; Loveridge, S.; Woods, M.; Zadorozhna, O. Security of property rights and transition in land use. J. Comp. Econ. 2016, 44, 76-91. [CrossRef]

32. Jin, X.; Xu, X.; Xiang, X.; Bai, Q.; Zhou, Y. System-dynamic analysis on socio-economic impacts of land consolidation in China Habitat Int. 2016, 56, 166-175. [CrossRef]

33. Faiz, M.A.; Liu, D.; Fu, Q.; Naz, F.; Hristova, N.; Li, T.; Niaz, M.A.; Khan, Y.N. Assessment of dryness conditions according to transitional ecosystem patterns in an extremely cold region of China. J. Clean. Prod. 2020, 255, 120348. [CrossRef]

34. Asabere, S.B.; Acheampong, R.A.; Ashiagbor, G.; Beckers, S.C.; Keck, M.; Erasmi, S.; Schanze, J.; Sauer, D. Urbanization, land use transformation and spatio-environmental impacts: Analyses of trends and implications in major metropolitan regions of Ghana. Land Use Policy 2020, 96, 104707. [CrossRef]

35. Liu, Y.; Long, H.; Li, T.; Tu, S. Land use transitions and their effects on water environment in Huang-Huai-Hai Plain, China. Land Use Policy 2015, 47, 293-301. [CrossRef]

36. Ge, D.; Wang, Z.; Tu, S.; Long, H.; Yan, H.; Sun, D.; Qiao, W. Coupling analysis of greenhouse-led farmland transition and rural transformation development in China's traditional farming area: A case of Qingzhou city. Land Use Policy 2019, 86, 113-125. [CrossRef]

37. Long, H.; Qu, Y. Land use transitions and land management: A mutual feedback perspective. Land Use Policy 2018, 74, 111-120. [CrossRef]

38. Barbier, E.; Tesfaw, A. Explaining forest transitions: The role of governance. Ecol. Econ. 2015, 119, 252-261. [CrossRef]

39. Sohl, T.; Sleeter, B.; Sayler, B.; Bouchard, M.; Reker, R.; Bennett, S.; Sleeter, R.; Kanengieter, R.; Zhu, Z. Spatially explicit land-use and land-cover scenarios for the Great Plains of the United States. Agr. Ecosyst. Environ. 2012, 153, 1-15. [CrossRef]

40. Zhang, Y.; Li, S.; Luo, T.; Gao, J. The effect of emission trading policy on carbon emission reduction: Evidence from an integrated study of pilot regions in China. J. Clean. Prod. 2020, 265, 121843. [CrossRef]

41. Hu, Y.; Ren, S.; Wang, Y.; Chen, X. Can carbon emission trading scheme achieve energy conservation and emission reduction? Evidence from the industrial sector in China. Energy Econ. 2020, 85, 104590. [CrossRef]

42. Tang, K.; Liu, Y.; Zhou, D.; Qiu, Y. Urban carbon emission intensity under emission trading system in a developing economy: Evidence from 273 Chinese cities. Environ. Sci. Pollut. Res. 2021, 28, 5168-5179. [CrossRef]

43. Jiang, J.J.; Ye, B.; Ma, X.M. The construction of Shenzhen's carbon emission trading scheme. Energy Policy 2014, 75, 17-21. [CrossRef]

44. Yang, X.; Jiang, P.; Pan, Y. Does China's carbon emission trading policy have an employment double dividend and a Porter effect? Energy Policy 2020, 142, 111492. [CrossRef]

45. Porter, M.E.; Van der Linde, C. Toward a new conception of the environment-competitiveness relationship. J. Econ. Perspect. 1995, 9, 97-118. [CrossRef]

46. Jiang, W. Does Environmental Regulation Affect R \& D Innovation of Manufacturing Firms in China? Empirical Study Based on Micro Data. J. Financ. Econ. 2015, 2, 76-87. [CrossRef] 
47. Zhou, C.B.; Tan, Y. The Impact of a Carbon Trading Pilot Policy on the Low-Carbon Economic Transformation in ChinaAn Empirical Analysis Based on a DID Model. Soft Sci. 2020, 10, 36-42. [CrossRef]

48. Hu, Q.; Huang, N. Can Market-Incentive Environmental Regulation Promote Corporate Innovation? A Natural Experiment Based on China's Carbon Emissions Trading Mechanism. J. Financ. Res. 2020, 1, 171-189.

49. Lv, M.; Bai, M. Evaluation of China's carbon emission trading policy from corporate innovation. Financ. Res. Lett. 2021, $39,101565$. [CrossRef]

50. Lyu, X.; Shi, A.; Wang, X. Research on the impact of carbon emission trading system on low-carbon technology innovation. Carbon Manag. 2020, 11, 183-193. [CrossRef]

51. Chen, Z.; Zhang, X.; Chen, F. Do carbon emission trading schemes stimulate green innovation in enterprises? Evidence from China. Technol. Forecast. Soc. Chang. 2021, 168, 120744. [CrossRef]

52. Dong, F.; Dai, Y.; Zhang, S.; Zhang, X.; Long, R. Can a carbon emission trading scheme generate the Porter effect? Evidence from pilot areas in China. Sci. Total Environ. 2019, 653, 565-577. [CrossRef] [PubMed]

53. Shen, C.; Li, S.; Wang, X.; Liao, Z. The effect of environmental policy tools on regional green innovation: Evidence from China. J. Clean. Prod. 2020, 254, 120122. [CrossRef]

54. Zhu, J.; Fan, Y.; Deng, X.; Xue, L. Low-carbon innovation induced by emissions trading in China. Nat. Commun. 2019, 10, 4088 [CrossRef] [PubMed]

55. Du, G.; Yu, M.; Sun, C.; Han, Z. Green innovation effect of emission trading policy on pilot areas and neighboring areas: An analysis based on the spatial econometric model. Energy Policy 2021, 156, 112431. [CrossRef]

56. Tang, H.L.; Liu, J.M.; Mao, J.; Wu, J.G. The effects of emission trading system on corporate innovation and productivity-empirical evidence from China's SO 2 emission trading system. Environ. Sci. Pollut. Res. 2020, 27, 21604-21620. [CrossRef]

57. Kohn, R.E. A general equilibrium analysis of the optimal number of firms in a polluting industry. Can. J. Econ. 1985, 18, 347-354. [CrossRef]

58. Coria, J. Taxes, permits, and the diffusion of a new technology. Resour. Energy Econ. 2009, 31, 249-271. [CrossRef]

59. Xie, Y.; Dai, H.; Zhang, Y.; Wu, Y.; Hanaoka, T.; Masui, T. Comparison of health and economic impacts of PM 2.5 and ozone pollution in China. Environ. Int. 2019, 130, 104881. [CrossRef]

60. Crowley, F.; McCann, P. Firm innovation and productivity in Europe: Evidence from innovation-driven and transition-driven economies. Appl. Econ. 2018, 50, 1203-1221. [CrossRef]

61. Li, X.; Hui, E.C.M.; Lang, W.; Zheng, S.; Qin, X. Transition from factor-driven to innovation-driven urbanization in China: A study of manufacturing industry automation in Dongguan City. China Econ. Rev. 2020, 59, 101382. [CrossRef]

62. Hong, Y.X. On the innovation-driven economic development. Economist 2013, 1, 5-11.

63. Snow, J. On the comparative mortality of large towns and rural districts, and the causes by which it is influenced. J. Public Health Sanit. Rev. 1855, 1, T16. [PubMed]

64. Obenauer, M.L. Effect of Minimum-Wage Determinations in Oregon: July, 1915 (No. 6); US Government Printing Office: Washington, DC, USA, 1915.

65. Meng, Y.; Wang, K.; Lin, Y. The Role of Land Use Transition on Industrial Pollution Reduction in the Context of Innovation-Driven: The Case of 30 Provinces in China. Land 2021, 10, 353. [CrossRef]

66. Tang, Y.; Chen, Y.; Wang, K.; Xu, H.; Yi, X. An Analysis on the Spatial Effect of Absorptive Capacity on Regional Innovation Ability Based on Empirical Research in China. Sustainability 2020, 12, 3021. [CrossRef]

67. Li, D.K.; Liu, L.L.; Wang, H.L. The U Curve of Labor Share in GDP during Economic Development. Econ. Res. J. $2009,1,70-82$.

68. Kuznets, S. Modern economic growth: Findings and reflections. Am. Econ. Rev. 1973, 63, 247-258.

69. Zhang, S.G. Promoting financial reform and adjusting monetary policy in accordance with the requirements of Marketization. J. Financ. 1996, 5, 8-10.

70. Trinh, T.H. A primer on GDP and economic growth. Int. J. Econ. Res. 2017, 14, 13-24.

71. Ahn, S.J.; Yoon, H.Y. 'Green chasm' in clean-tech for air pollution: Patent evidence of a long innovation cycle and a technological level gap. J. Clean. Prod. 2020, 272, 122726. [CrossRef]

72. Wang, H.M.; Xie, Y.L.; Sun, J. Study on the "action" game and synergy factors of air pollution control in Beijing-Tianjin-Hebei under different situation. China Popul. Resour. Environ. 2019, 29, 20-30.

73. Shan, Y.; Guan, D.; Zheng, H.; Ou, J.; Li, Y.; Meng, J.; Mi, Z.; Liu, Z.; Zhang, Q. China CO 2 emission accounts 1997-2015. Sci. Data 2018, 5, 170201. [CrossRef]

74. Shan, Y.; Huang, Q.; Guan, D.; Hubacek, K. China $\mathrm{CO}_{2}$ emission accounts 2016-2017. Sci. Data 2020, 7, 54. [CrossRef] [PubMed] 